\title{
Effect of Surface Roughness on Copper Corrosion in Simulated Beishan Groundwater, China
}

\author{
Minglei Hu ${ }^{1}$, Wei Zhang ${ }^{2, *}$, Xianhe Shang ${ }^{1}$, Jie Wen ${ }^{1}$, Zhenjiang Zhao ${ }^{2}$, Bingxuan Qiao ${ }^{2}$, Decheng \\ Kong ${ }^{2}$, Chaofang Dong ${ }^{2, *}$ \\ ${ }^{1}$ China Nuclear Power Operation Management Co., Ltd, Zhejiang 314300, China \\ 2 Institute for Advanced Materials and Technology, University of Science and Technology Beijing, \\ Beijing 100083, China \\ *E-mail: huml@cnnp.com.cn, 15201461811@163.com
}

doi: $10.20964 / 2020.04 .05$

Received: 8 October 2019/ Accepted: 4 December 2019 / Published: 10 March 2020

The simulated Beishan groundwater of preselected area for high level nuclear waste disposal was prepared and the effect of surface roughness on corrosion behavior of copper was characterized by potentiodynamic polarization, immersion tests and scanning electrochemical microscope (SECM) measurements. It was found that as the surface roughness increased, the corrosion activity of copper was accelerated. Meanwhile, the corrosion current decreased by around $85.6 \%$ as the roughness values decreased from approximately $2.34 \mu \mathrm{m}$ to $0.33 \mu \mathrm{m}$ and there was no much change after further polishing. The SECM results showed that the corrosion current near the scratch was much higher than the smooth region, which meant a high oxygen consumption in scratch positions and indicated that surface irregularities led to a preferential dissolution and corrosion.

Keywords: Copper corrosion; Beishan groundwater; Surface roughness; Scanning electrochemical microscope; Nuclear waste disposal.

\section{$\underline{\text { FULL TEXT }}$}

(C) 2020 The Authors. Published by ESG (www.electrochemsci.org). This article is an open access article distributed under the terms and conditions of the Creative Commons Attribution license (http://creativecommons.org/licenses/by/4.0/). 